\title{
DP-INTERNAL SUBJECTS
}

\author{
YUJI TAKANO \\ University of Tsukuba
}

\begin{abstract}
This paper deals with some asymmetries related to 'DP-internal' subjects, subjects of noun phrases in the traditional sense. It is shown that while all DP-internal subjects surface in the same form, that is, in the genitive form, their syntactic behavior varies depending upon their thematic status: the Arg phrase, which is inherently related to the head $\mathrm{N}$, and the Poss phrase, which is not, exhibit surprising differences in behavior with respect to control, binding and extraction, which suggests that the two types of DP-internal subject should not be considered syntactically uniform. On the basis of these considerations, it is argued that such asymmetries can be explained in a revealing way under the minimal hypothesis that the Poss phrase is different from the Arg phrase in that the former is categorially a PP rather than a DP*
\end{abstract}

0. IntRoduction. It is well known that the structural notion 'subject-of' as defined by Chomsky 1965 is readily generalized to include the case of genitive phrases within noun phrases, as exemplified in 1:

(1) a. John's car

b. the enemy's destruction of the city

Assuming that noun phrases are DPs rather than NPs, as argued in the recent literature, let us call these genitive phrases DP-INTERNAL SUBJECTS.

There are two views on the structural treatment of DP-internal subjects: one is that all DP-internal subjects have an equal syntactic status, that is, that of an adjunct, and the other is that there are two types of DPinternal subject. The former view is advocated by Zubizarreta 1985 and Grimshaw 1986, and the latter by Stowell 1989 and Takano 1988, among others. It seems that the following contrast discussed by Stowell 1989, who attributes the original observation to Chomsky, supports the latter

* I am grateful to Minoru Nakau, Yukio Hirose, Shin Watanabe, Keiko Miyagawa and Kazue Takeda for helpful comments on an earlier draft, and to two anonymous EL reviewers whose suggestions improved this paper. Ronald Craig is to be greatly thanked for his discussions with me about the English data.

English Linguistics 7 (1990) 105-128 -105-

(C) 1990 by the English Linguistic Society of Japan 
view: ${ }^{1}$

(2) a. Who did you sell a picture of?

b. ??Who did you sell Mary's picture of? (Mary = Arg)

c. *Who did you sell Mary's picture of? $($ Mary $=$ Poss)

It is obvious from 2 that a DP-internal subject affects the possibility of extraction, but the degree to which it makes extraction difficult varies depending upon its thematic status.

In this paper I will claim, essentially along the same lines as Takano 1988, that there are really two types of DP-internal subject, ARG and Poss, by showing that the contrast in 2 can be subsumed under the general 'Arg/Poss asymmetries', instances of which are also found in empirical domains other than extraction, and that these asymmetries' can be explained in a principled way. ${ }^{2}$

1. ARg/Poss asymmetries. In 2 we looked at an interesting asymmetry between Arg and Poss with respect to extraction, as a starting point of discussion. In this section I will point out that there exist other kinds of $\mathrm{Arg} /$ Poss asymmetry as well.

1.1. Rationale Clause licensing. Since Roeper 1983 it has often been argued that contrasts like 3 reflect a purely syntactic phenomenon:

(3) a. the enemy, 's destruction of the city [PRO $\mathrm{P}_{\mathrm{i}}$ to win the war]

b. *the city's destruction by the enemy [PRO to win the war] Roeper argues that for a rationale clause to be licensed, its subject PRO must be controlled. Thus $3 \mathrm{a}$ is grammatical since PRO is controlled by the Arg phrase, the enemy, while $3 \mathrm{~b}$ is ill-formed since PRO lacks a controller.

There is another type of contrast concerning the licensing of rationale clauses. Consider the following:

(4) a. John ${ }_{\mathrm{i}}$ 's thesis $\left[\mathrm{PRO}_{\mathrm{i}}\right.$ to get his degree]

${ }^{1}$ By 'Arg' and 'Poss' I mean the phrase inherently related to the head N (typically Agent, but including Source/Goal and 'preposed' Theme within 'passive' nominals), and the phrase without such inherent relation to N (typically Possessor), respectively. As argued by Williams 1982 , the Poss phrase can bear any semantic relation to $\mathrm{N}$ that is permitted in a particular context. I will use Arg and Poss as cover terms throughout the discussion.

${ }^{2}$ Stowell's approach to the contrast in 2 is different from the one that will be proposed later. As will be clear, however, his approach does not cover the facts in section 1 below. 
b. $\mathrm{John}_{\mathrm{i}}$ 's speeches $\left[\mathrm{PRO}_{\mathrm{i}}\right.$ to win the election]

(5) a. *John's cat [PRO to anger his mother]

b. *John's destruction of Rome [PRO to prove a point]

5 is different from $3 \mathrm{~b}$ in that John might count as a controller; nevertheless, the examples are ungrammatical. Notice that the fact that these examples are bad cannot be treated on semantic grounds, given that as Williams 1982 observes, John's cat and John's destruction of Rome can mean 'the cat John stepped on' and 'John's account of the destruction of Rome', respectively, and that these meanings are fairly compatible with the meaning of a rationale clause. Nor can the ungrammaticality be attributed to the 'non-process' status of the nominal head, considering the grammaticality of 4 , where each example contains a non-process nominal, thesis and speeches. Rather, an important distinction seems to lie in the fact that in 3a and 4 DP-internal subjects are Arg while in 5 they are Poss. Thus the contrast between $3 \mathrm{a}$ and 4 on the one hand, and 5 on the other is considered to be a second instance of $\mathrm{Arg} / \mathrm{Poss}$ asymmetries. ${ }^{3}$

1.2. ANAPHORIC BINDING. It has been well known that DP-internal subjects create opaque domains for anaphors, yielding the so-called Specified Subject Condition (SSC) effects, as shown in 6:

(6) a. ${ }^{*}$ The $m^{2} n_{i}$ read [Mary's stories about each other ${ }_{i}$ ].

b. The men $_{\mathrm{i}}$ read [Mary's stories about them $\mathrm{m}_{\mathrm{i}}$.

(Fukui and Speas 1986)

Apparently, these observations suggest that all occurrences of DP-internal subjects affect the possibility of anaphoric binding. In fact, however, this is not the case, contrary to the widely accepted view: as observed in the recent literature, there are examples, such as those in 7, in which DPinternal subjects do not count as 'specified subjects':

(7) a. Tom ${ }_{i}$ told Dick [Mary's story about himself $f_{i}$.

(Nakajima 1984)

b.(?)The men $_{\mathrm{i}}$ read [yesterday's stories about each other $\mathrm{i}_{\mathrm{i}}$.

(Fukui and Speas 1986)

c. John $_{\mathrm{i}}$ saw [Mary's picture of himself $\mathrm{i}$ ]. (Mary $=$ Poss)

(Oka 1986, Saito 1986)

3 The 'preposed' Theme in a 'passive' nominal can license a rationale clause:

(i ) John ${ }_{\mathrm{i}}$ 's arrest $t_{\mathrm{i}}$ by the police $\left[\mathrm{PRO}_{\mathrm{i}}\right.$ to impress his mother]

This fact indicates that the relevant distinction should be made between Arg and Poss rather than between Agent and Poss. See note 1. 
It appears that a crucial factor for the lack of SSC effects in the above examples is the fact that each DP-internal subject is Poss. ${ }^{4}$ Since anaphoric binding is constrained by condition $\mathrm{A}$ of binding theory, these facts exhibit another instance of Arg/Poss asymmetries that falls under condition A. ${ }^{5}$

1.3. Pronominal Coreference. Pronouns must not have antecedents that are 'too close' to them in some intuitive sense. Thus the examples in 8 are ruled out, as compared with those in 9 , since the pronouns and their antecedents are too close to each other (brackets indicate the domains where pronouns must not be bound):

(8) a. *[John ${ }_{\mathrm{i}}$ loves him $\left._{\mathrm{i}}\right]$.

b. ${ }^{*}\left[\mathrm{John}_{\mathrm{i}}\right.$ believes $\mathrm{him}_{\mathrm{i}}$ to be intelligent $]$.

(9) a. John i loves [his $_{\mathrm{i}}$ mother].

b. $\mathrm{John}_{\mathrm{i}}$ believes [(that) Mary loves him ] $^{\text {] }}$.

Traditionally, it has been argued that a DP-internal subject and a pronoun that is a complement of $\mathrm{N}$ are too close in this sense to have coreference

${ }^{4}$ The example given below, which was pointed out by Anderson 1983, may be problematic:

(i ) $*$ They $_{\mathrm{i}}$ saw my cards from each other ${ }_{\mathrm{i}}$ on my desk.

If $m y$ is Poss, which apparently seems to be the case, the sentence should be grammatical. But note that the possessor and the recipient of a card usually coincide; as a matter of fact, under the most unmarked reading (i) is synonymous with (ii):

(ii) They ${ }_{i}$ saw the cards to me from each other $_{i}$ on my desk.

Thus the DP-internal subject in (i) is most likely interpreted to be an argumental (Goal) element of cards, which is Arg in the present terms (see note 1). If this is a correct description of (i), it is no longer a problem: the Arg phrase prevents the binding relation from holding between they and each other. This treatment in turn leads us to predict that if a particular context forces the DP-internal subject in question to be unambiguously understood as Poss, the resulting structure will improve, which is borne out:

(iii) a. ??They ${ }_{\mathrm{i}}$ saw my cards to Mary from each other $\mathrm{r}_{\mathrm{i}}$ ( $m y=$ 'my copy of')

b. They ${ }_{i}$ saw last year's cards to me from each other . .

5 There seems to be a possibility that an empty Arg phrase, PRO, is syntactically present within DP and makes the sentences in 7 grammatical, as Fukui and Speas 1986 suggest for $7 \mathrm{~b}$ and Giorgi 1987, for similar facts in Italian. There are several counterarguments to such an analysis, however. Hoji 1988 and Barss 1988 argue convincingly that there is no PRO syntactically projected within a 'non-process' noun phrase, on the basis of the facts concerning the bound variable interpretation and the reciprocal interpretation. Since the examples in 7 contain non-process nominals, I will not appeal to PRO. For the lines of approach that appeal to the implicit arguments of the head N, see Saito 1986, 1987 and Oka 1986. 
relation. Thus the following is a well-known contrast:

(10) a. John ${ }_{i}$ 's examination of himself $f_{i}$

b. ${ }^{*} J_{o h n}$ 's examination of him $_{\mathrm{i}}$

From this one might conclude, as seems natural, that all DP-internal subjects cannot be the antecedents of pronouns within DP.

Again, however, this is not always the case: the following examples seem to allow coreference between John and him if the former is understood to be Poss:

(11) a. [John ${ }_{\mathrm{i}}$ 's book about him $\left._{\mathrm{i}}\right]$

b. $\left[\mathrm{John}_{\mathrm{i}}\right.$ 's picture of $\left.\operatorname{him}_{\mathrm{i}}\right]$

Although the grammatical judgments are subtle, 11 is better than $10 \mathrm{~b}$, which is hopelessly bad under a coreference interpretation. Thus it follows that there exist Arg/Poss asymmetries within the range of condition $\mathrm{B}$, too.

1.4. Condition $C$ effects. Briefly, condition $C$ states that R-expressions must not be bound by other R-expressions or pronouns. Thus the following sentences are excluded by this condition:

(12) a. ${ }^{*} \mathrm{John}_{\mathrm{i}} / \mathrm{He}_{\mathrm{i}}$ hates $\mathrm{John}_{\mathrm{i}}$ ('s mother).

b. ${ }^{*} \mathrm{John}_{\mathrm{i}} / \mathrm{He}_{\mathrm{i}}$ believes (that) Mary hates $\mathrm{John}_{\mathrm{i}}$.

Contrary to expectation, two R-expressions with the same referential value can appear within DP, one being a DP-internal subject and the other a complement of $\mathrm{N}$, as shown in 13:

(13) a. John ${ }_{\mathrm{i}}$ 's book about $\mathrm{John}_{\mathrm{i}}$

b. $\mathrm{John}_{\mathrm{i}}$ 's picture of $\mathrm{John}_{\mathrm{i}}$

But again this is possible only under the interpretation in which each DPinternal subject is Poss. Although the well-known prohibition in English, regarded as extra-grammatical in nature, against repetition of Rexpressions makes these examples slightly odd even under Poss interpretation (see Lasnik 1989), this repetition constraint is too weak to account for the sharp contrast between Arg and Poss.

So far we have seen one case of condition $\mathrm{C}$ effects, where a binder is an R-expression. How about the other case? At this point I must admit that pronominal DP-internal subjects, even in the case of Poss, seem to render coreference much more difficult than in 13 :

(14) a. ?*his i $_{\mathrm{i}}$ book about $\mathrm{John}_{\mathrm{i}}$

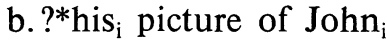

Apparently, we face a serious problem with the above conclusion that Arg/Poss asymmetries affect the empirical domain relevant to condition 
C. We will return to this problem in the next section.

1.5. Bound PRONOUNS. It is well known that in certain contexts pronouns are interpreted as bound variables, as in 15:

(15) Everyone $e_{i}$ believes that he $e_{i}$ is intelligent.

Although the exact syntactic relation that is necessary and sufficient to license the bound variable interpretation of pronouns is still at issue (see Barss 1988 and references cited there), we can informally state, for present purposes, the following:

(16) For a pronoun $\mathrm{P}$ to be bound as a variable by a QP, $\mathrm{P}$ must be c-commanded by both the QP and (the container of) its trace after QR at LF.

15 meets the condition in 16 since the pronoun is c-commanded by both everyone and its trace at LF, as shown in 17:

(17) [Everyone $e_{i}\left[t_{i}\right.$ believes that $\mathrm{he}_{\mathrm{i}}$ is intelligent]] Apparently, the following example might refute 16 :

(18) a. *Everyone ${ }_{i}$ hates him $_{i}$.

b. [Everyone $\mathrm{i}_{\mathrm{i}}\left[t_{\mathrm{i}}\right.$ hates him $\left.\left._{\mathrm{i}}\right]\right]$

Here both QP and its trace c-command the pronoun at LF; nevertheless, the sentence is ungrammatical under the intended interpretation. However, there is an independent reason for the ungrammaticality: being a pronoun, him is subject to condition $\mathrm{B}$, and this very condition is violated in 18 , just as in 8 above. It is predicted, then, that 18 will become grammatical if QP is contained in another phrase, and this is indeed the case:

(19) a. [Everyone,'s mother] loves him hi $_{i}$

b. [Everyone $e_{i}\left[\left[t_{i}\right.\right.$ mother] loves him hi $\left._{\mathrm{i}}\right]$.

At LF him is c-commanded by everyone and the container of its trace ([ $t_{\mathrm{i}}$ mother]), satisfying 16 .

Keeping this in mind, let us turn to our main concern: if a DP-internal subject is QP, does it license the bound variable interpretation of a pronoun inside DP? Consider the relevant examples:

(20) a. everyone $e_{i}$ 's book about $\operatorname{him}_{i}$

b. everyone $e_{i}$ 's picture of him $_{i}$

Again, the judgments are not entirely clear, but there seems to be a significant difference in acceptability between Arg and Poss: if DP-internal subjects are interpreted as Arg, the bound variable interpretation is never obtained, whereas Poss seems to license it. The explanation of the fact that Arg can never license the bound variable interpretation is straightforward: it is explained by condition $\mathrm{B}$, as is 18 . Then it follows that what 
needs a principled explanation is the fact that Poss renders 20 acceptable.

2. Structural differences between Arg and Poss. Although the observations made in the previous section include subtle judgments, perhaps due to the fact that the relevant DP-internal subjects are ambiguous between Arg and Poss, we have seen that asymmetries do exist between Arg and Poss. Since these observations are purely syntactic in nature, it is obvious that they cannot be explained on the view held by Zubizarreta 1985 and Grimshaw 1986 that all DP-internal subjects are adjuncts syntactically. In this section I will put forward a hypothesis concerning the Poss phrase in the spirit of Stowell 1989 and Takano 1988: Arg and Poss phrases are syntactically different.

2.1. The PP Poss Hypothesis. Consider the following contrast cited from Anderson 1978:

(21) a. [Yesterday's lecture] will be given tomorrow.

b. *[The lecture yesterday] will be given tomorrow.

The sentence in $21 \mathrm{~b}$ is odd because 'what is done cannot be undone'. Thus it is 21a that needs accounting for. Anderson remarks that yesterday's lecture can mean 'the lecture scheduled for yesterday'. This fact suggests that the temporal noun phrase yesterday acquires an additional meaning when it is used as a DP-internal subject, and that this additional meaning makes the whole sentence semantically coherent. This 'extra meaning' phenomenon evokes the assertion that Poss can mean anything. One way to substantiate this claim is to suppose that a Poss phrase is contained in another category, in which it receives an extra meaning; more specifically, that a Poss phrase is a PP whose head, a phonologically empty $\mathrm{P}$, assigns the contained phrase (DP) a Poss role, whose interpretation is determined by a context and because of which 21a makes sense. Let us call this the PP Poss HyPothesis.

Adopting the Revised DP Hypothesis of Takano 1989 for the internal structure of noun phrases, we understand that the structure of a noun phrase containing a Poss phrase is as follows: ${ }^{6}$

${ }^{6}$ The Revised DP Hypothesis states that the internal structure of noun phrases is three-layered, as represented in (i):

(i ) [DP D [IP I [NP N]]]

Nominal INFL assigns genitive Case to an element in the SPEC of IP in just the same way as nominative Case assignment by verbal INFL ('s is considered to be a real- 
(22) a. yesterday's lecture

b. [DP1 [IP [PP $e$ [DP2 yesterday]] I [NP lecture]]]

Focusing on the Poss phrase, I will refer to the containing PP and the contained DP2 as Poss PP and Poss DP, respectively. The structure 22b contrasts with that of a noun phrase containing an Arg phrase, as shown in 23:

(23)
a. Chomsky's lecture
b. [DP [IP [DP Chomsky] I [NP lecture]]]

A few words about Case-marking are in order. Given that $\mathrm{P}$ and $\mathrm{I}$ are Case-markers, it follows that in 23b nominal INFL assigns genitive Case to DP Chomsky, whereas in 22b it assigns this Case to Poss PP and Poss DP yesterday gets Case from the empty P. Here again 's is considered to be a realization of genitive Case (see note 6). ${ }^{7}$

The PP Poss Hypothesis thus proposed seems to be supported by the following facts:

(24) a. *[The lectures last year] will be given next year.

b. [Last year's lectures] will be given next year.

c. [The lectures of last year] will be given next year.

(25) a. *[The blackouts in New York] occurred in Los Angeles.

b.(?)[New York's blackouts] occurred in Los Angeles.

c. [The blackouts of New York] occurred in Los Angeles.

The (a) examples above do not make any sense, just like 21b. Note that the extra meaning phenomenon can be found not only in the case of a Poss phrase but also in the case of a PP whose head is of. Thus we understand that the empty $\mathbf{P}$ in 22 carries out the same function as does the

ization of genitive Case). From an X-bar theoretic point of view, DP is defective in that it is SPEC-less. This is argued to be due to the defective character of D with respect to the SPEC-head agreement features in the sense of Fukui 1986. The idea that DP includes nominal IP was originally put forth by Tonoike 1988, but the Revised DP Hypothesis is different from his proposal in several important respects. For more details, see Takano 1989 and Tonoike 1989.

7 As Yukio Hirose (personal communication) has pointed out to me, the PP Poss Hypothesis is incompatible with the claim that the ungrammaticality of such examples as (i) reflects their categorial status as PPs:

(i ) *then's/now's/there's/here's lecture

(ii) the lecture then/now/there/here

Although the proper treatment of the so-called 'bare-NP adverbs' is beyond the scope of this paper, I claim that the ungrammaticality of (i) has nothing to do with their categorial status, and can be explained on other grounds. For a proposal along these lines, see Larson 1985. 
overt preposition of in 24 and 25.

2.2. Consequences for Arg/Poss asymmetries. The PP Poss Hypothesis put forth above has direct consequences for the Arg/Poss asymmetries pointed out in section 1 . To begin with, let us consider the asymmetries concerning rationale clause licensing. The fact that needs explanation is that Poss cannot license a rationale clause, in contrast to Arg. The relevant examples are repeated here as 26:

(26) a. the enemy's destruction of the city $\left[\mathrm{PRO}_{i}\right.$ to prove a point]

b. $\mathrm{John}_{\mathrm{i}}$ 's thesis $\left[\mathrm{PRO}_{\mathrm{i}}\right.$ to get his degree]

c. $\mathrm{John}_{\mathrm{i}}$ 's speeches $\left[\mathrm{PRO}_{\mathrm{i}}\right.$ to win the election]

d. *John's cat [PRO to anger his mother]

e. *John's destruction of Rome [PRO to prove a point]

The PP Poss Hypothesis correctly rules out the last example since it assigns the Poss phrase a PP structure as in $22 \mathrm{~b}$, because of which the Poss DP John does not c-command and hence does not license PRO in the rationale clause.

Next turn to the facts observed in 6a and 7, repeated here as 27 and 28, which fall within the range of condition A of binding theory:

(27) ${ }^{*}$ The men $_{i}$ read [DP [IP Mary's stories about each other $\left.{ }_{i}\right]$.

(28) a. [IP Tom ${ }_{i}$ told Dick [DP [IP Mary's story about himself $\left.\left.f_{\mathrm{i}}\right]\right]$ ]. b.(?)[IP The men $_{\mathrm{i}}$ read [DP [IP yesterday's stories about each other $\left.\left.\left.{ }_{\mathrm{i}}\right]\right]\right]$.

c. [IP $\mathrm{John}_{\mathrm{i}}$ saw [DP [IP Mary's picture of himself $\left.\left.\mathrm{i}_{\mathrm{i}}\right]\right]$.

Informally, condition A states that an anaphor must be bound within its governing category, the minimal domain containing a lexical governor and a possible binder. ${ }^{8}$ If a DP-internal subject counts as a possible binder of an anaphor inside DP, as is the case with Arg, then the latter must be bound by the former, since the governing category of such an anaphor is (nominal) IP, which is the mininal domain containing a lexical governor, $\mathrm{P}$, and a possible binder, the DP-internal subject; hence the ungrammaticality of 27. If a DP-internal subject is Poss as in 28, the PP Poss Hypothesis provides a binding loophole for an anaphor inside DP:

${ }^{8}$ Chomsky 1986a defines governing categories in terms of the notion Complete Functional Complex (CFC), which is the domain that contains all the grammatical functions compatible with its head. According to this definition, verbal and nominal IPs can be governing categories under my system. 
the Poss PP defines the c-command domain of the contained Poss DP, and the latter does not count as a possible binder of an anaphor outside the former. Thus the governing categories of the anaphors in 28 are the matrix IPs, in which condition A is satisfied.

A potential problem might arise at this point: it must be ensured that a Poss PP does not count as a possible binder, since the governing categories of the anaphors in 28 would otherwise be nominal IPs. ${ }^{9}$ As has been observed in the literature, expletives do not create opaque domains for anaphors. We can attribute this fact to their non-referential nature, since binding theory concerns referential dependencies. In this connection it is interesting to note that 'prepositional' subjects as in [Under the garden] is buried a picture, which are also non-referential, do not count as possible binders:

(29) $\mathrm{John}_{\mathrm{i}}$ thinks that [under the garden] is buried a picture of himself ${ }_{i}$.

As for Poss PPs, they do not have a referential function, either. Thus we can maintain that they do not create opaque domains for anaphors (we will see other syntactic properties of prepositional subjects in section 3 ).

Let us turn to the facts concerning condition $\mathrm{B}$. The relevant examples in 11 are given below as 30, where each John is Poss:

(30) a. [DP [IP John ${ }_{\mathrm{i}}$ 's book about him $\mathrm{i}$ ]]

b. [DP [IP John,'s picture of him $\mathrm{i}$ ]]

Condition B states that a pronoun must be free within its governing category, which is the minimal domain containing a lexical governor. Thus for the pronouns in 30 their governing categores are (nominal) IPs, which are the minimal domains containing lexical governors, about and of. If the John's in 30 were Arg, the him's would be bound by them and violate condition B. But the PP Poss Hypothesis prevents them from violating it, since Poss DP does not c-command outside its containing Poss PP.

The facts concerning condition $\mathrm{C}$ can be treated in the same way. Consider the relevant examples in 13 , repeated as 31 , where each DPinternal subject is Poss:

(31) a. John',s book about $\mathrm{John}_{\mathrm{i}}$

b. John ${ }_{i}$ 's picture of $\mathrm{John}_{\mathrm{i}}$

9 This point has been brought to my attention by Kazue Takeda (personal communication). 
Given that condition $\mathrm{C}$ requires R-expressions to be free, it must be the case that the second occurrences of John above are not bound by the first ones, and this is possible with the help of the PP Poss Hypothesis. Needless to say, if a DP-internal subject is Arg, there is no way to prevent the examples from violating condition $\mathrm{C}$.

Recall that we have apparent counterexamples to the conclusion that Poss does not cause condition $\mathrm{C}$ violations. Observe the following examples containing Poss phrases, which were given as 14 earlier:

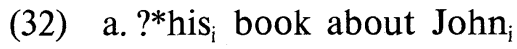

b. ?*his picture of $\mathrm{John}_{\mathrm{i}}$

In this connection it is worth noting the fact that pronouns behave differently from R-expressions in certain respects within the empirical domain of condition $C$. In general, parasitic gaps are licensed within adjuncts, as shown below:

(33) What $t_{\mathrm{i}}$ did you file $t_{\mathrm{i}}$ [before you read $e_{\mathrm{i}}$ ]?

It has been claimed in the literature that the licensing condition of parasitic gaps includes an 'anti-c-command' requirement of some sort, which states that neither of the true gap and the parasitic gap must ccommand the other.

However, there are facts that appear to be incompatible with this claim. Contreras 1984 and Chomsky 1986b point out that 'backward coreference' is difficult in examples like 34b:

(34) a. We interviewed [his $\mathrm{i}_{\mathrm{i}}$ parents] [before we admitted $\mathrm{John}_{\mathrm{i}}$ ]

b. ?*We interviewed him $_{\mathrm{i}}$ [before we admitted $\mathrm{John}_{\mathrm{i}}$ ].

The difficulty of coreference between the pronoun and the R-expression in 34b might suggest that such coreference violates condition C. This in turn suggests that the adjunct clause is c-commanded by the direct object of the verb. Interestingly enough, however, this does not hold when the direct object is an R-expression (again, we abstract away from the slight oddness resulting from the repetition of R-expressions):

(35) We interviewed $\mathrm{John}_{\mathrm{i}}$ [before we admitted $\mathrm{John}_{\mathrm{i}}$ ].

It is obvious that the contrast between $34 \mathrm{~b}$ and 35 is just parallel to the contrast between 31 and 32 .

One way to solve this puzzle is to introduce a 'relaxed' notion of ccommand: suppose, essentially following Chomsky 1986b, that in a configuration like $36 \alpha$ 'weakly' c-commands $\beta$ though $\alpha$ does not ccommand $\beta$ in a strict sense, in case $\gamma$ is a segment or PP:

(36) $\left.{ }_{\delta} \beta[\gamma \ldots \alpha \ldots] \beta\right]$, where $\gamma$ defines a c-command domain of $\alpha$ and $\delta$ defines c-command domain of $\gamma$. 
It then follows that the direct object of V and Poss DP 'weakly' c-command the VP adjunct and the element external to Poss PP, respectively. Suppose further that this weak c-command satisfies the anti-c-command requirement of parasitic gaps and condition $\mathrm{C}$, hence the grammaticality of 31,33 and 35 , but that when a pronoun weakly c-commands an Rexpression, as in 32 and $34 \mathrm{~b}$, it violates another condition independent of condition C: the condition proposed by Lasnik 1989, which prevents a less referential expression, a pronoun, from binding a more referential one, an R-expression. In other words, I am claiming that 'bind' in the sense of Lasnik's condition should be defined in such a way as to include weak c-command, so that this condition rules out the examples in 32 despite the PP Poss Hypothesis (we will return to this point in 2.3.1. below). Therefore I conclude that the facts in 32 do not refute the PP Poss Hypothesis.

Finally, the facts concerning the bound variable interpretation can be explained on the same grounds as pronominal coreference. Thus QPs appearing as Poss phrases can satisfy condition 16 after QR without violating condition $\mathrm{B}$, because of the PP Poss Hypothesis.

2.3. SOME RELATED PROBlems. Up to this point we have seen that the otherwise mysterious asymmetries between Arg and Poss that were noted in section 1 immediately follow from the PP Poss Hypothesis. In this sense this hypothesis is well motivated. On the other hand, it seems to raise new problems with binding, control and the licensing of Poss PP. In the remainder of this section I will touch on these problems in turn.

2.3.1. Binding AND Control. Suppose that the PP Poss Hypothesis prevents the contained Poss DP from binding other elements outside Poss PP. This immediately faces a problem: if Poss DP cannot bind outside Poss PP, it can never bind an anaphor inside a noun phrase, which clearly is not the case, as shown in 37 :

(37) a. John read [Mary's book about herself $f_{i}$.

b. John saw [Mary ${ }_{i}$ 's picture of herself $f_{i}$.

Here both examples are acceptable not only when their DP-internal subjects are Arg but when they are Poss. Thus to maintain that Poss PP always prevents Poss DP from binding outside it would be too strong.

I have claimed, however, that Poss DP 'weakly' c-commands outside Poss PP (see the discussion on the contrast between 31 and 32). This will solve the problem with 37 . Recall that weak c-command satisfies condi- 
tion C. Let us extend this idea to conditions A and B. It then follows that in 37 Poss DP Mary can weakly c-command herself, hence satisfying condition A. In fact, there seems to be evidence that this is not peculiar to covert Poss PP but is true also of (at least some) overt PPs in English. Consider the following:

(38) a. John talked [with Mary $\left.{ }_{i}\right]_{\text {about herself }}$.

b. It seems [to John and Mary ${ }_{i}$ ] that each other ${ }_{i}$ 's friends are kind.

c. John wrote it [with Mary ] $_{\mathrm{i}}$ about herself $\mathrm{i}_{\mathrm{i}} / \mathrm{her}_{\mathrm{i}}$.

d. They wrote that story [with Mary $\left.]_{\mathrm{i}}\right]_{\text {with herself }} /$ her $_{\mathrm{i}}$ as the main character.

e. ?*It seems [to him ${ }_{\mathrm{i}}$ ] that $\mathrm{John}_{\mathrm{i}}$ is a genius.

f. It seems [to $\mathrm{John}_{\mathrm{i}}$ ] that $\mathrm{John}_{\mathrm{i}}$ is a genius.

The examples (a) and (b) indicate that weak c-command satisfies condition A, and (c) and (d), that it satisfies condition B at the same time. ${ }^{10}$ The significant contrast between (e) and (f) shows that weak c-command does not violate condition $\mathrm{C}$ but leads to a violation of Lasnik's condition, a conclusion reached above.

In effect, we can state informally that a weakly c-commanding element 'optionally' counts as a (possible) binder in the sense of the binding conditions (hence the grammaticality of both 28 and 37), whereas such an element is 'necessarily' regarded as a binder within Lasnik's condition. Since the Poss phrase and the overt PP are quite similar in behavior with respect to binding theory, the claim that the Poss phrase is a PP is supported empirically.

Obviously, the conclusion that weak c-command suffices for binding in the sense of the binding conditions cannot be carried over to control, however. If it were, it would be incorrectly predicted that $26 \mathrm{~d}$ and $26 \mathrm{e}$ are grammatical, with Poss DP John controlling PRO:

(26) d. *John's cat [PRO to anger his mother]

e. *John's destruction of Rome [PRO to prove a point]

${ }^{10}$ Weak c-command cannot satisfy condition A in German, as the following examples from Grewendorf 1985 suggest:

(i ) a. *Hans spricht [mit Maria ${ }_{\mathrm{i}}$ ] über $\operatorname{sich}_{\mathrm{i}}$.

'John spoke with Mary about herself.'

b. Hans spricht [mit Maria ${ }_{i}$ ] über sie i $_{\text {. }}$

'John spoke with Mary about her.'

Thus it appears that there is a parameter with respect to the choice of $\gamma$ in 36 . 
Suppose in this connection that the c-command requirement in control theory is somewhat different from that in the binding conditions; more specifically, that control requires 'strict' c-command in contrast to the binding conditions, which allow for weak c-command. Again there seems to be evidence that this is true in general:

(39) a. John loaded the wagon ${ }_{i}\left[\mathrm{PRO}_{\mathrm{i}}\right.$ full] with hay.

b. John loaded the hay $\mathrm{i}_{\mathrm{i}}$ into the wagon $\left[\mathrm{PRO}_{\mathrm{i}}\right.$ green].

c. *John loaded the wagon [with hay] [PRO green].

d. *John loaded the hay [into the wagon] [PRO full].

(Williams 1980, Stowell 1983)

If we adopt Stowell's small clause approach to quasi-predicates, a crucial factor in licensing them is control. ${ }^{11}$ Then we can say that $39 \mathrm{c}$ and $39 \mathrm{~d}$ are ill-formed since within PP hay and the wagon cannot control PRO: control theory requires strict c-command. ${ }^{12}$ If the Poss phrase and the overt PP behave similarly with respect to control, then the PP Poss Hypothesis receives additional empirical justification.

Notice that within the modular approach assumed here it is not unreasonable to maintain that different subtheories or conditions appeal to different notions of c-command. Thus the apparent problems with the PP Poss Hypothesis that are related to binding and control can be resolved in sufficiently general terms, which suggests that the hypothesis itself is fairly promising.

2.3.2. LiCENSING of Poss PP. One question remains to be answered. Recall that the PP Poss Hypothesis put forth earlier in this section is twofold: it states that the Poss phrase is categorially a PP, and that it occurs in the SPEC of nominal IP. Thus far, I have not argued for the validity of the second claim. In this connection there are two pieces of evidence that the Poss phrase must be in the SPEC of nominal INFL.

11 For different approaches from Stowell's, see Williams 1980 and Kayne 1985.

12 The following examples might pose a problem to the position that control requires strict c-command:

(i) a. I pushed $\mathrm{it}_{\mathrm{i}}$ over [to $\mathrm{John}_{\mathrm{j}}$ ] $\left[\mathrm{PRO}_{\mathrm{j}}\right.$ to use $e_{\mathrm{i}}$ on his hamburger].

b. I left it $\mathrm{i}_{\mathrm{i}}$ [with $\mathrm{John}_{\mathrm{j}}$ ] [PRO $\mathrm{PR}_{\mathrm{j}}$ to use $e_{\mathrm{i}}$ as he pleases].

c. [For you $\mathrm{u}_{\mathrm{i}}$ ] it is important $\left[\mathrm{PRO}_{\mathrm{i}}\right.$ to behave yourself].

(Jones 1985)

Note, however, that these constructions, but not those in the text, allow the so-called arbitrary PRO in the absence of an overt controller, which suggests that they involve different kinds of control (though the exact nature of each kind is unclear). Thus it appears that the existence of examples like (i) does not invalidate my argument. 
One is found in Hungarian. Hungarian is a language that exhibits overt agreement between a DP-internal subject and the head N. According to Szabolcsi 1984, agreement takes place irrespective of the type of DP-internal subject, that is, whether it is a 'process' or 'non-process' nominal. Under the Revised DP Hypothesis assumed here, this indicates unambiguously that the Poss phrase necessarily appears in the SPEC of nominal IP, triggering SPEC-head agreement. It is highly unlikely, from the viewpoint of UG, that the Poss phrase in English (or for that matter, in any language) is different in this respect, even though agreement is not overt.

The other piece of evidence is concerned with the English genitive marker 's. We have considered this marker to be a morphological realization of genitive Case (see 2.1.). Hence it follows that the obligatory presence of 's on the Poss phrase implies that genitive Case is always assigned to that phrase. This in turn suggests that the Poss phrase must be in the SPEC of nominal IP, since under the Revised DP Hypothesis, genitive Case marking takes place only in that position.

What, then, licenses the Poss phrase, namely Poss PP under the PP Poss Hypothesis, in that position? If nothing forces it to occur there, there will be no reason to believe that Poss PP is in that very position, and not any other. I would like to suggest that this problem is related to the Case-marking property of the head of Poss PP. Specifically, it might be assumed that the empty $\mathbf{P}$ is somewhat defective in that it Case-marks its complement only if it itself is Case-marked. If this is true, it will follow that Poss PP must occur in an Case-marked position in order for its head, an empty $P$, to Case-mark Poss DP, which needs Case. This rather peculiar property of the empty P might be regarded as parallel to those of the Accusative-ING in English (see Reuland 1983) and of the inflected infinitival INFL in Portuguese (see Raposo 1987): these three must be Case-marked if they are to Case-mark other elements. ${ }^{13}$

13 I have not yet explained the fact that an overt PP, unlike a Poss PP, never appears as a DP-internal subject:

(i ) *[of last year]'s lectures

I suggest that the solution of this problem is related to the assumption made in the text that a Poss PP, but not an overt PP, needs Case. In Takano 1989 I argue, roughly following Fukui 1986, that the SPEC is licensed by the Case features of its head, and that verbal INFL always has these features, whereas nominal INFL can optionally be feature-less. The latter claim amounts to saying that the SPEC of verbal IP is always present to be occupied by some element, while nominal IP can be SPEC-less when its 
3. The PP Poss Hypothesis and extraction. The PP Poss Hypothesis thus proposed, interacting with Case theory and bounding theory, has an interesting consequence for the Arg/Poss asymmetry with respect to extraction, which was noted at the outset but left unexplained.

3.1. CASE THEORY AND 'NON-NOMINAL' SUBJECTS. To begin with, let us examine one of the syntactic properties of PP from a Case theoretic point of view. It is well known that PP shows the same distributional behavior as CP (or IP). Thus it does not appear in positions where 'structural' Case in the sense of Chomsky 1986a is assigned. Consider 40 and 41:

(40) a. John is certain [CP that he will win].

b. John $n_{\mathrm{i}}$ is certain [IP $t_{\mathrm{i}}$ to win].

c. John is certain [PP of his victory].

(41) a. *John believes [CP that he will win] to be certain.

b. *John believes [CP (for Mary) to win] to be certain.

c. *John believes [pP of his victory] to be certain.

(cf. Oka 1986)

Both CP and PP are excluded from the subject position of the 'Exceptional Case-marking' context, where structural Case-marking typically takes place. ${ }^{14}$

$\mathrm{CP}$ is also excluded (except for a few instances) from the object position of P. Interestingly, however, as Stowell 1981 and Oka 1986, 1988 observe, if such a CP is topicalized, the sentence becomes grammatical:

(42) a. *We'll look into [that the water might be dirty].

b. ?[That the water might be dirty $]_{\mathrm{i}}$, we'll look into $t_{\mathrm{i}}$ tomorrow.

(43) a. *Mary is certain $(*$ of) [that John will win].

head has no Case features. From the viewpoint of the 'least effort' guidelines of Chomsky 1989, this in turn means that the SPEC of nominal IP is licensed only when it holds an element requiring Case, because it will cost more for nominal INFL to Case-mark (that is, license) its SPEC than not to do so, for an element requiring no Case. Since an overt PP requires no Case, the least effort principle forces it to appear in an adjunct position (to the right of $\mathrm{N}$ in English) to be licensed as an adjunct, as in (ii):

(ii) the lectures [of last year]

On the other hand, as suggested in the text, a Poss PP cannot be licensed without Case; hence it must occur in the SPEC of nominal IP in order to get Case.

${ }^{14}$ Following Zubizarreta 1985 and Oka, I regard an of-phrase as a PP, contrary to the claims that it is inserted at S-structure (see Chomsky 1981) or that it is merely a realization of inherent Case (see Chomsky 1986a). 
b. [That John will win $]_{i}$, I am certain *(of) $t_{\mathrm{i}}$.

In order to explain these facts within Case theory, Oka 1988, extending Chomsky's 1986a notion of 'inherent' Case and Stowell's Case Resistance Principle, proposes the following Case Realization Principle:

(44) a. Structural Case is not realized on a category with a SC feature.

b. Inherent Case is not realized on a category without a SC feature.

Here a SC feature means a feature assigning structural Case. Given that CP has a SC feature while its trace does not (see Oka 1988), it follows from this principle that $\mathrm{CP}$ and its trace behave in exactly the opposite way: CP can appear in a position assigned an inherent Case but not in a structurally Case-marked position, whereas its trace can appear in the latter position but not in the former.

Another position that is assigned structural Case is the SPEC of tensed IP, where nominative Case is assigned by verbal INFL. Apparently, CP can occur in that position, an instance of 'sentential' subjects. Such sentential subjects, however, behave quite differently from 'nominal' subjects, as pointed out in the literature. One remarkable difference is that sentential subjects block Subject-Aux Inversion, in contrast to nominal subjects:

(45) a. *Is [that the world is round] obvious?

b. *Is [for John to solve the problem] necessary?

c. Is [the fact that the world is round] obvious?

To account for this fact, Stowell 1981 proposes that they move to a topic position, as an instance of string vacuous topicalization, in order to avoid a violation of his Case Resistance Principle. Let us adopt this approach here. Given that verbal INFL assigns structural (nominative) Case, it follows that Oka's Case Realization Principle forces this structural Case to be realized on other categories than sentential subject $\mathrm{CP}$, and that it can be realized on the trace of topicalized CP. Then we understand that the same situation arises in 46 as in $42 \mathrm{~b}$ and $43 \mathrm{~b}$, as represented in 47 :

(46) a. [That the earth is round] is obvious to everyone.

b. [For you to do this] is necessary.

(47) a. [That the earth is round $]_{i} t_{i}$ is obvious to everyone.

b. [For you to do this $]_{\mathrm{i}} t_{\mathrm{i}}$ is necessary.

Now let us turn to another peculiar property of sentential subjects. Sentential subjects affect the possibility of extraction, as shown below:

(48) a. I think that [for John to visit Mary] would bother Bill. 
b. I think that [John's visit to Mary] would bother Bill.

c. ?? $\mathrm{Who}_{\mathrm{i}}$ do you think that [for John to visit Mary] would bother $t_{i}$ ?

d. $\mathrm{Who}_{\mathrm{i}}$ do you think that [John's visit to Mary] would bother $t_{\mathrm{i}}$ ?

If we assume that sentential subjects undergo string vacuous topicalization, we can account for this rather peculiar fact. Lasnik and Saito (forthcoming) observe that topicalization constitutes an island, as shown in 49:

(49) a. ??the man to whom ${ }_{\mathrm{i}}$ that book $_{\mathrm{j}}$, I gave $t_{\mathrm{j}} t_{\mathrm{i}}$

b. ??the place where $e_{\mathrm{i}}$ that book $_{\mathrm{j}}$, John put $t_{\mathrm{j}} t_{\mathrm{i}}$

They argue convincingly that topicalized elements are adjoined to IP. Then it is conceivable that sentential subjects are also adjoined to IP. Thus, as a descriptive generalization, we can say as follows:

(50) A category created by adjunction constitutes a barrier. ${ }^{15}$ Given that extraction of an argument across a barrier only 'weakly' violates the Subjacency condition, resulting in marginality (see Chomsky 1986b and Lasnik and Saito (forthcoming)), it is obvious that the facts in $48 \mathrm{c}$ and 49 can be subsumed under the generalization in 50 .

It is interesting to note that the same situation arises in the case of 'prepositional' subjects as well. Consider the following examples cited from Baker 1988:

(51) a. [On the table] was put a book.

b. [In the garden] was killed a man.

The simplest assumption about 51 is that the prepositional subject is the subject of the sentence (see Baker 1988). ${ }^{16}$ If this is correct, it is predict-

${ }^{15}$ Lasnik and Saito propose the system of barriers that covers 50, which will not concern us here.

${ }^{16}$ Specifically, the prepositional subject appears in the SPEC of IP as a 'place holder' in order to satisfy the requirement that nominative Case of verbal INFL be discharged, and/or the Extended Projection Principle. Perhaps the direct object of the (passive) verb is assigned what Belletti 1988 calls 'partitive Case', or its head undergoes what Baker calls 'covert' Incorporation into the verb, satisfying the Case filter.

Note that prepositional subjects in my sense do not include all instances of clauseinitial PPs. I refer to clause-initial PPs that exhibit the following properties as prepositional subjects:

(i ) They can appear in embedded tensed clauses: I believe that [under the garden] is buried a picture of John.

(ii ) They cannot be embedded under the so-called ECM verbs: *I believe [under the garden] to be buried a picture of John.

(iii) Their occurrences are restricted by the requirement that the thematic 
ed by Oka's Case Realization Principle 44 that this PP adjoins to IP since $P$ has a SC feature, just as sentential subjects do, as in 52:

(52) [IP [PP On the table $]_{\mathrm{i}}$ [IP $t_{\mathrm{i}}$ was put a book]]

This analysis in turn predicts the semi-grammaticality of argument extraction since the upper IP constitutes an 'adjunction' barrier according to 50 , and the crossing of one barrier causes a weak violation of Subjacency. In fact, this prediction is borne out:

(53) a. I think that [in this city] can be visited several interesting places.

b. I think that [several interesting places] can be visited in this city.

c. ??What $t_{\mathrm{i}}$ do you think that [in this city] can be visited $t_{\mathrm{i}}$ ?

d. In which city ${ }_{\mathrm{i}}$ do you think that [several interesting places] can be visited $t_{\mathrm{i}}$ ?

Now we have evidence that sentential subjects and prepositional subjects exhibit quite parallel behavior, in contrast to nominal subjects. Then it is fairly reasonable to group them together as 'non-nominal' subjects. ${ }^{17}$

3.2. BOUNDING THEORY AND DP-INTERNAL SUBJECTS. Now we are in a position to explain the contrast in 2, which exhibits an Arg/Poss asymme-

objects be indefinite: *[Under the garden] is buried the picture/it.

Thus those instances of clause-initial PPs that lack any of these properties are not regarded as prepositional subjects.

${ }_{17}$ An anonymous EL reviewer has pointed out that the following facts are problematic to the present analysis of prepositional subjects:

(i) a. [Under the bed] is a comfortable place.

b. Is [under the bed] a comfortable place?

c. How comfortable [under the bed] is!

If these examples involve prepositional subjects, their complete grammaticality poses a problem. However, there are reasons to believe that the bracketed phrases in (i) are not instances of prepositional subjects in the present sense. Consider the following examples from Jaworska 1986:

(ii) a. They considered [after the holidays] to be too late for a family gathering.

b. [Under the chair] attracted the cat's attention.

The relevant PPs lack two of the properties given in note 16 . Hence the examples in (i) pose no problem to the present analysis.

Notice that prepositional subjects do block Subject-Aux Inversion:

(iii) a. *Was [on the table] put a book?

b. *Was [in the garden] killed a man?

Thus this is an additional piece of evidence for considering sentential and prepositional subjects to constitute a natural class. 
try with respect to extraction:

(2) a. Who did you sell [DP a picture of $t_{\mathrm{i}}$ ]?

b. ?? $\mathrm{Who}_{\mathrm{i}}$ did you sell [DP Mary's picture of $t_{\mathrm{i}}$ ] ( Mary $\left.=\mathrm{Arg}\right)$

c. ${ }^{*} \mathrm{Who}_{\mathrm{i}}$ did you sell [DP Mary's picture of $t_{\mathrm{i}}$ ] (Mary $=$ Poss)

First of all, let us examine 2a. In Takano $1989 \mathrm{I}$ argue that extraction out of DP always crosses one barrier, DP, because of the SPEC-less nature of DP under the Revised DP Hypothesis (see also section 2). It then follows that $2 \mathrm{a}$ is a weak violation of Subjacency even though it sounds perfectly acceptable. In fact, I claim, it parallels examples like 54, where whphrases have been extracted out of infinitival $w h$-islands:

(54) a. Who do you know [how to get along with $t_{\mathrm{i}} t_{\mathrm{j}}$ ]?

b. To whom ${ }_{\mathrm{i}}$ did you wonder [what $\mathrm{t}_{\mathrm{j}}$ to give $t_{\mathrm{j}} t_{\mathrm{i}}$ on Christmas day]?

These examples also sound fine. On the other hand, adjuncts cannot be extracted at all out of DP (see Takano 1989) or out of infinitival whislands (see Chomsky 1986b). Given that adjunct extraction across a barrier yields a completely unacceptable sentence while a weak violation of Subjacency yields a fairly acceptable sentence (see Chomsky 1986b), my claim that extraction out of DP crosses a barrier is confirmed.

The fact that $2 \mathrm{~b}$ and 55 , which is also from Stowell 1989, are marginal suggests that another barrier is crossed, and that this barrier is related to the presence of the DP-internal subject, which is Arg.

(55) ?? $\mathrm{Who}_{\mathrm{i}}$ does Jane regret [DP Bob's dismissal of $t_{\mathrm{i}}$ ]?

In Takano 1989 this problem is solved by proposing some modification of Chomsky's 1986b notion of 'weak' barriers: 'Case-marking IPs' rather than 'tensed IPs' constitute weak barriers. ${ }^{18}$ This modification covers examples like $2 \mathrm{~b}$ and 55 , where the relevant DP includes a Case-marking nominal IP, as well as those like 56, where the relevant $\mathrm{CP}$ includes a Case-marking verbal IP:

(2) b. ??Who did you sell [DP [IP Mary's picture of $t_{i}$ ]]?

(56) a. ??What ${ }_{\mathrm{i}}$ do you know [CP how [IP John explained $\left.t_{\mathrm{i}}\right]$ ??

b. ??Who ${ }_{i}$ do you wonder [CP when [IP John visited $\left.t_{\mathrm{i}}\right]$ ?

Thus $2 \mathrm{~b}$ and 56 each involve the crossing of one strong barrier and one weak barrier: DP and nominal IP in the former, and CP and verbal IP in

${ }^{18}$ By 'Case-marking IP' I mean the IP whose head Case-marks its SPEC. From now on I will refer to the barrier that is not weak as a 'strong' barrier for terminological reasons. 
the latter. Since a weak barrier yields weaker effects, the examples in $2 b$ and 56 are not violations as severe as a strong violation of Subjacency, which is caused by the crossing of two strong barriers (but notice their lessened acceptability, as compared with 2a and 54).

Finally, let us turn to 2 c, our main concern in this paper. Similar examples cited from Pustejovsky 1984 are given below:

(57) a. *What ${ }_{i}$ did Mary drink [DP John's bottles of $t_{\mathrm{i}}$ ]?

b. *the city $\mathrm{i}_{\mathrm{i}}$ that we heard [DP your destruction of $t_{\mathrm{i}}$ ] (your $=$ 'your account of') Again, these examples have DP-internal subjects in common; but in this case they are Poss phrases, which are argued to be PPs under the PP Poss Hypothesis. Recall that we saw in 3.1. that prepositional subjects and sentential subjects are grouped together as 'non-nominal' subjects: they adjoin to IP for Case theoretic reasons, and the IP to which they adjoin constitutes a barrier because of 50 .

These considerations give us the desired results. Consider the S-structure representation of $2 \mathrm{c}$ below:

(58) $\mathrm{Who}_{\mathrm{i}} \ldots$ [DP $_{\mathrm{DP}}\left[{ }_{\mathrm{PP}} e \text { Mary }\right]_{\mathrm{j}}\left[{ }_{\mathrm{IP}} t_{\mathrm{j}} \mathrm{I}\right.$ [NP picture of $\left.\left.\left.\left.t_{\mathrm{i}}\right]\right]\right]\right]$ Being a PP, Poss PP adjoins to nominal IP. Extraction of who crosses at least two strong barriers: IP' $^{\prime}$ is an adjunction barrier and DP is a barrier that inherits barrierhood from nominal IP (see Chomsky 1986b). Thus in $2 \mathrm{c}$ a strong violation of Subjacency results. It follows that $2 \mathrm{c}$ corresponds to extraction out of a relative clause, which typically causes a strong Subjacency violation, as in 59:

(59) *What language ${ }_{\mathrm{i}}$ did you meet [DP a girl [CP who speaks $\left.t_{\mathrm{i}}\right]$ ]? Here, according to Chomsky, at least two strong barriers, DP and CP, are crossed. ${ }^{19}$

Notice in passing that nominal IP plays a crucial role in explaining the marginality of $2 b$ and the ungrammaticality of $2 c$ : it creates a weak barrier in $2 \mathrm{~b}$ and an adjunction barrier in $2 \mathrm{c}$. This indicates that nominal IP interacts with bounding theory in a revealing way, lending additional theoretical support to the proposal for introducing the projection of INFL into DP, namely, the Revised DP Hypothesis.

Now a few words about the adjoined Poss phrase are in order. Recall that I have claimed in 2.3.2. that the Poss phrase (namely, Poss PP) must

19 Strictly speaking, the movements in $2 \mathrm{c}$ and in 59 involve one more barrier: a weak barrier as a Case-marking IP. 
appear in the SPEC of nominal IP. At first glance, to say that the Poss phrase is adjoined to nominal IP would contradict this claim. This is not the case, however. I have maintained that the Poss phrase must agree with nominal INFL and must be Case-marked by it. This is possible through its trace left behind in the SPEC even though the Poss phrase itself is not in the SPEC of nominal IP. Thus we can transfer to its trace what we assumed held for the Poss phrase itself.

To sum up, we have seen that instances of the Arg/Poss asymmetry phenomenon concerning extraction represented by the minimal contrast between $2 \mathrm{~b}$ and $2 \mathrm{c}$ can be explained in terms of Subjacency under the PP Poss Hypothesis.

4. Concluding Remarks. The theme of this paper has been the asymmetry related to DP-internal subjects, namely the asymmetry between Arg and Poss. We have seen that the range of data pointed out as instances of this asymmetry can be explained in a principled way in terms of the PP Poss Hypothesis, which in turn gains strong support from it. This hypothesis states that the Poss phrase is categorially a PP. It seems that this is not a radical move from the viewpoint of the current theory; for as always, the theoretical justification for positing such a null PP is the need to capture significant syntactic generalizations in an appropriate way.

Although space limitations preclude a thorough discussion, I would like to add that the sort of Arg/Poss asymmetry phenomenon discussed in this paper seems to be found in Japanese as well. Thus it is desirable from the viewpoint of UG that the proposed analysis can be carried over to Japanese and other languages that exhibit the same phenomenon. This is an intriguing topic for future research.

Finally, the present analysis has interesting implications for the issue of argument projection inside DP: it suggests that the Arg/Poss distinction should be made even in the case of 'non-process' nominals, which have often been argued to be non-theta assigners, since the data treated here largely involve such nominals. ${ }^{20}$ If this is correct, it will be necessary to construct a system of argument projection in which non-process nominal

${ }^{20}$ Extraction phenomena also imply that such a distinction should be made with respect to PPs appearing inside non-process noun phrases: some behave like arguments and others like adjuncts. See Takano 1989 for more details. 
heads also take argumental elements. Of course, we have to leave this matter to future research, too.

\section{REFERENCES}

ANderson, Mona. 1978. NP pre-posing in noun phrases. NELS 8.12-21.

-. 1983. Prenominal genitive NPs. The Linguistic Review 3.1-24.

Baker, Mark. 1988. Incorporation. Chicago: University of Chicago Press.

BARSS, ANDREw. 1988. Comments on the paper by Hoji: Null nominal subjects and constraints on bound pro. Proceedings of Japanese syntax workshop, ed. by Wako Tawa and Mineharu Nakayama, 112-31. Connecticut College.

Belletti, Adriana. 1988. The Case of unaccusatives. LI 19.1-34.

Chomsky, Noam. 1965. Aspects of the theory of syntax. Cambridge, MA: MIT Press.

-. 1981. Lectures on government and binding. Dordrecht: Foris.

- 1986a. Knowledge of language: Its nature, origin, and use. New York, NY: Praeger.

—. 1986b. Barriers. Cambridge, MA: MIT Press.

- 1989. Some notes on economy of derivation and representation. MIT working papers in linguistics 10.43-74.

Contreras, Heles. 1984. A note on parasitic gaps. LI 15.698-701.

FUKUI, NAOKI. 1986. A theory of category projection and its applications. MIT dissertation.

Fukui, Naoki, and Margaret Speas. 1986. Specifiers and projection. MIT working papers in linguistics 8.128-72.

Giorgi, Alessandra. 1987. The notion of complete functional complex: Some evidence from Italian. LI 18.511-18.

GrEWENDORF, GüNTER. 1985. Anaphoren bei Objekt-Koreferenz im Deutschen: Ein Problem für die Rektions-Bindungs-Theorie. Erklärende Syntax des Deutschen, ed. by Werner Abraham, 137-71. Tubingen: Gunter Nall.

GrIMSHAW, JANE. 1986. Nouns, arguments and adjuncts. MS. Brandeis University.

HoJi, HAJIME. 1988. Empty pronominals in Japanese and subject of NP. Proceedings of Japanese syntax workshop, ed. by Wako Tawa and Mineharu Nakayama, 94-111. Connecticut College.

JAWORSKA, Ewa. 1986. Prepositional phrases as subjects and objects. Journal of Linguistics 22.355-74.

Jones, Charles. 1985. Syntax and thematics of infinitival adjuncts. UMass dissertation.

KAYNE, Richard. 1985. Principles of particle constructions. Grammatical representation, ed. by Jacqueline Guéron, Hans-Georg Obenauer and Jean-Yves Pollock, 101-40. Dordrecht: Foris.

LARSON, RICHARD. 1985. Bare-NP adverbs. LI 16.595-621.

LASNIK, HowARD. 1989. Essays on anaphora. Dordrecht: Kluwer.

LASNIK, Howard, and Mamoru Saito. Forthcoming. Move-alpha: Conditions on 
its application and output.

NakaJima, Heizo. 1984. COMP as a SUBJECT. The Linguistic Review 4.121-52.

Ока, Tоshifusa. 1986. Inherent Case. Tsukuba English Studies 5.123-66.

- 1988. Expanding the Case module. MS. University of Tsukuba.

Pustejovsky, JAMES. 1984. Studies in generalized binding. UMass dissertation.

RAPOSO, EDUARDO. 1987. Case theory and Infl-to-Comp: The inflected infinitive in

European Portuguese. LI 18.85-109.

Reuland, ERIC. 1983. Governing -ing. LI 14.101-36.

RoEPer, Thomas. 1983. Implicit arguments and lexicon. MS. UMass.

SaIto, ShinjI. 1986. On control into NP. Tsukuba English Studies 5.67-86.

-. 1987. Some puzzles of anaphoric binding and levels of control. Tsukuba English Studies 6.17-33.

Stowell, Tiмотнy. 1981. Origins of phrase structure. MIT dissertation.

—. 1983. Subjects across categories. The Linguistic Review 2.285-312.

- 1989. Subjects, specifiers, and X-bar theory. Alternative conceptions of phrase structure, ed. by Mark Baltin and Anthony Kroch, 232-62. Chicago: University of Chicago Press.

Szabolcsi, AnNa. 1984. The possessor that ran away from home. The Linguistic Review 3.89-102.

TAKANo, YuJI. 1988. Syntactic aspects of noun phrases in English. M.A. thesis, University of Tsukuba.

- 1989. Some extensions of the DP hypothesis. English Linguistics 6.90-110.

TonoIKe, Shigeo. 1988. Nichieigo hikaku tougoron. Gengo 17, 5.82-88.

- 1989. The comparative syntax of English and Japanese: Relating unrelated languages. [To appear, Current English linguistics in Japan, ed. by Heizo Nakajima. The Hague: Mouton.]

Williams, Edwin. 1980. Predication. LI 11.203-38.

- . 1982. The NP cycle. LI 13.277-95.

ZubizarReTa, MaRia. 1985. The relation between morphophonology and morphosyntax: The case of Romance causatives. LI 16.247-89. 